\title{
Penerapan Face Recognition dengan Metode Eigenface pada Intelligent Car Security
}

\author{
Sehman \\ Teknologi Informasi \\ Sekolah Tinggi Teknologi Surabaya \\ Sehman08agustus@yahoo.com
}

\begin{abstract}
ABSTRAK
Kemajuan teknologi informasi telah banyak di manfaatkan dalam bidang keamanan terlebih disaat tindakan kriminal meningkat terutama dari pencurian. Mobil merupakan salah satu target unit yang harus di tingkatkan keamanannya, banyak para ahli menciptakan jenis keamanan pada mobil. Penulis mencoba untuk lebih mengembangkan dengan memanfaatkan Metoda Eigenface. Eigenface merupakan metoda yang memiliki prinsip kerja dengan menggunakan file XML dalam melakukan Recognition Face (pendeteksian wajah), hal ini hampir sama halnya dengan Face Detection. Pengaplikasian Face Recognition ini memiliki database berupa informasi wajah pemilik mobil yang sebelumnya telah disimpan kemudian dibandingkan oleh wajah yang telah ditangkap dan menghasilkan informasi baru berupa pengenalan wajah yang akan mengaktifkan alarm dan penguncian mobil otomatis.
\end{abstract}

Kata kunci: Eigenface, File XML Pengenalan Wajah, Keamanan Mobil.

\section{ABSTRACT}

The development of information technology have been utilized on the security settings. Car is one of the target unit that should get it's security improved, many experts create the kind of security on the car. The author tries to further develop car security by using eigenface method. Eigenface is a method which has the working principle using XML Files in performing face recognition (face detection), it is almost the same as face detection. The application of face recognition have database which contains information on car owners face, a process previously saved then compared by a face that has been captured and produce new information in the form of identification face that will activate the car alarm and automatic locking.

Key Word: Eigenface, XML files, Face Recognition, Car Security,

\section{PENDAHULUAN}

Sistem keamanan mobil saat ini telah berkembang pesat, akan tetapi sistem tersebut masih memiliki kekurangan dan tidak dapat secara langsung menangkap pelaku pencurian. Sistem pada face recognition car security bekerja sebagai pengenal wajah aktif pada mobil. Jika sistem ini menangkap wajah yang berbeda dengan pemilik mobil maka aplikasi akan membunyikan alarm peringatan bersamaan dengan penguncian 
otomatis pintu dan hanya dapat di buka oleh kunci pemilik mobil tersebut, sehingga pelaku pencuri akan mudah di tangkap.

\section{DASAR TEORI}

Face Recognition pernah dilakukan oleh Mukti dengan menggunakan metoda Fracta Neighbour Distance. Hal ini digunakan untuk menyamakan suatu gambar yang belum teridentifikasi dari gambar yang ada di dalam database. Input diperlukan dalam aplikasi ini adalah citra wajah dengan ukuran dan resolasi yang sama. Hasil output aplikasi ini ialah hasil pencocokan byte pixel yang didapat dari hasil pemindaian dengan informasi byte pixel gambar yang ada didalam database. Kouma Jean Paul dalam tesisnya yang berjudul Inteligent Home Security System menggunakan Face Recognition untuk mengenali siapa saja yang tinggal didalam rumah dan jika system mendeteksi sesuatu yang dianggap mengganggu maka system akan mengirim MMS wajah pengganggu kepada pemilik rumah, system akan mati secara otomatis jika system mendeteksi salah satu penghuni rumah. Dan akan aktif kembali ketika seluruh penghuni meninggalkan rumah. Sudah banyak algoritma yang digunakan dalam pengenalan wajah, seperti kohenen, nearest, feature midpoint, canonical correlation analysis, Eigenface. Di dalam paper ini, penulis memanfaatkan metoda eigenface, namun akan dilakukan lebih lanjut sehingga sistem dapat mengenali wajah siapa yang berada di dalam mobil, tentunya didukung oleh beberapa metoda lain seperti haarsacade. Serangkaian Eigenvektor yang digunakan untuk mengenali wajah manusia dalam suatu computer vision merupakan konsep dari eigenface yang akan disajikan dimana Eigenvektor itu berasal dari covariance matrix yang memiliki distribusi probabilitas yang tinggi dan dimensi ruang vektor untuk mengenali sebuah wajah.

\section{PERANCANGAN SISTEM}

\subsection{Perancangan Sistem Pengenalan Objek/Penangkapan Wajah}

Paper yang berjudul Penerapan Face Recognition dalam Inteligent Car Security dengan menggunakan Metoda Eigenface ini memiliki beberapa tahap dalam pengenalan wajah yaitu:

1. Menghitung gambar dari jarak tersebut dan di bandingkan dengan gambar gambar yang terdapat di dalam database.

2. Memiih sebuah gambar yang terdapat didalam database dan membandingkan kemiripan dari gambar yang di deteksi.

3. Bila gambar yang telah di ukur tersebut hasilnya melebihi dari nilai threshold maka gambar tersebut dikenali oleh system dan jika gambar yang diukur memiliki nilai lebih kecil dari threshold maka gambar tidak dikenali oleh system karena sistem hanya mengenal gambar yang berada di database yang telah disimpan sebelumnya.

4. Menghidupkan alarm saat terdeteksi wajah yang tidak dikenali dan beriringan dengan penutupan pintu otomatis. 
Bagan di bawah ini menjelaskan system berjalan dalam proses penangkapan dan penyimpanan wajah.

Tabel.1 Ilustrasi alur sistem berjalan

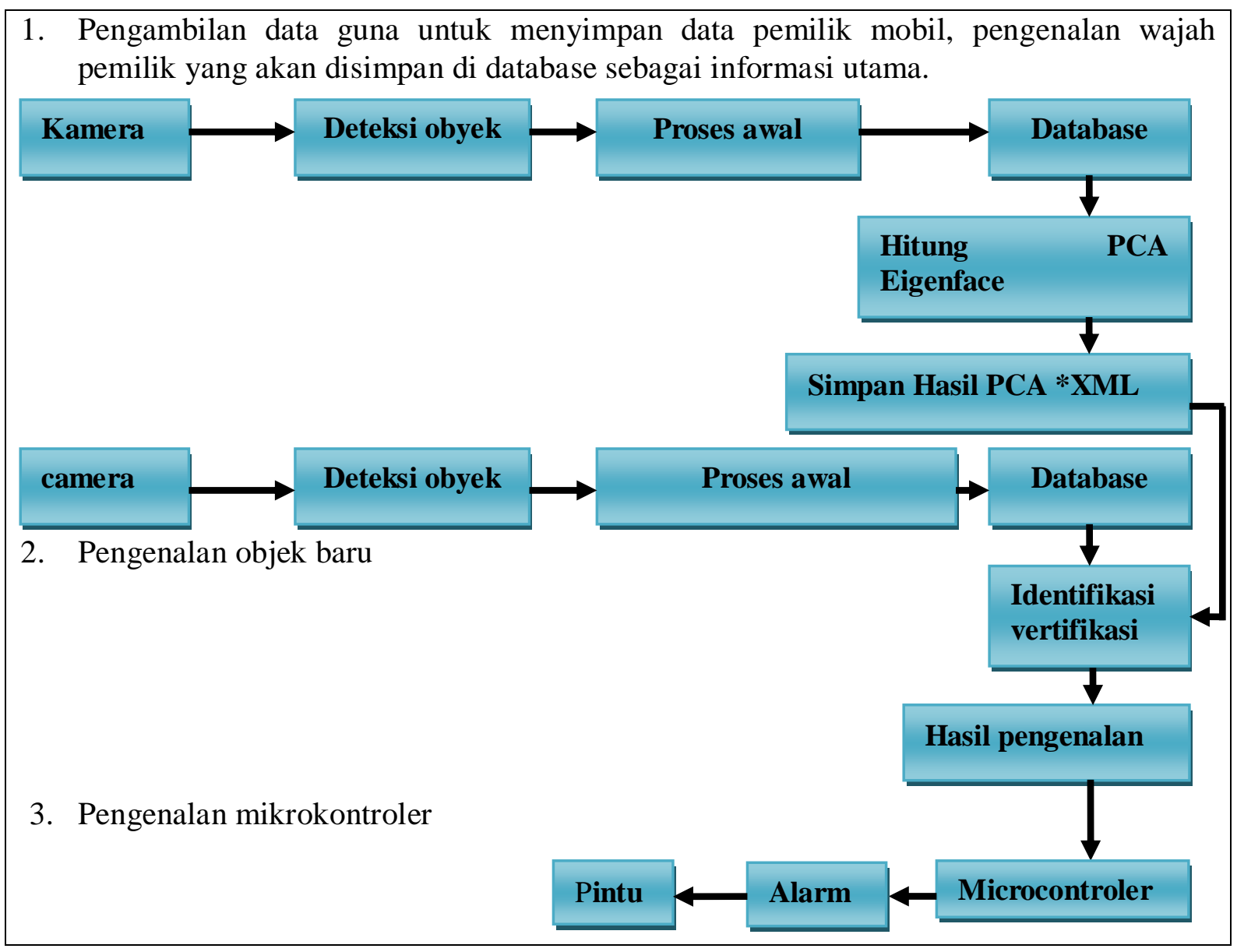

Tabel 1 merupakan penjelasan langkah pertama dalam pengambilan data pemilik mobil yang akan disimpan didalam database, kemudian dilanjutkan langah kedua pengenalan wajah dan langkah ketiga pengirim perbedaan nilai ke mikrocontroler guna untuk memberikan informasi baru. Proses jalannya system adalah sebagai berikut

1. Kamera akan selalu aktif didalam mobil dengan menggunakan daya dari aki mobil, kamera mengenali wajah (deteksi obyek), mengirimnya ke aplikasi kemudian menghitung nilai dan hasilnya akan berupa gambar wajah yang akan ditampilkan di LCD

2. Penghitungan nilai meliputi normalisai ukuran citra, RGB ke Grayscale, Historgram, resize atau normalisasi pencahayahaan ketika menangkap gambar sehingga hanya bagian wajah saja yang akan dihitung dan wajah akan tersimpan dengan gambar berbentuk *.Pgm.

3. Kemudian dilakukan proses PCA dengan metoda Eigenface sehingga mendapatkan Eginvector dan eigenvalue.

4. Di simpan ke dalam database dengan ekstensi sebagai pembanding pada proses penghitungan jarak untuk pengenalan wajah. 
Pada bagan yang kedua dijelaskan seperti berikut

1. Kamera akan selalu aktif di dalam mobil, dimana pertama kamera mengenali wajah (deteksi obyek) mengirimnya ke aplikasi kemudian menghitung nilai dan hasilnya akan berupa gambar wajah yang akan ditampilkan di LCD.

2. Penghitungan nilai meliputi normalisai ukuran citra, RGB ke Grayscale, Histogram, resize atau normalisasi pencehayahaan ketika menangkap gambar sehingga hanya bagian wajah saja yang akan dihitung dan wajah akan tersimpan dengan gambar berbentuk *.Pgm.

3. Kemudian dilakukan proses PCA dengan metoda Eigenface sehingga mendapatkan Eigenvector dan Eigenvalue.

4. Perbandingan wajah baru dengan wajah yang telah disimpan di database dengan menghitung antara fitur wajah, jarak yang didapat dicari nilai yang terkecil untuk perbandingan.

Pada bagan yang ketiga dijelaskan seperti berikut

1. Setelah hasil perbandingan di temukan maka dari database system akan mengirim ke controller.

2. Jika nilai wajah baru lebih kecil dari nilai thershold maka wajah baru itu tidak dikenali dan system microkontroler akan otomatis mengunci pintu dan membunyikan alarm.

3. Jika nilai wajah baru lebih besar dari nilai thershold maka wajah baru itu dikenali dan sistem microcontroller akan berjalan manual sesuai kerja dari pengemudi.

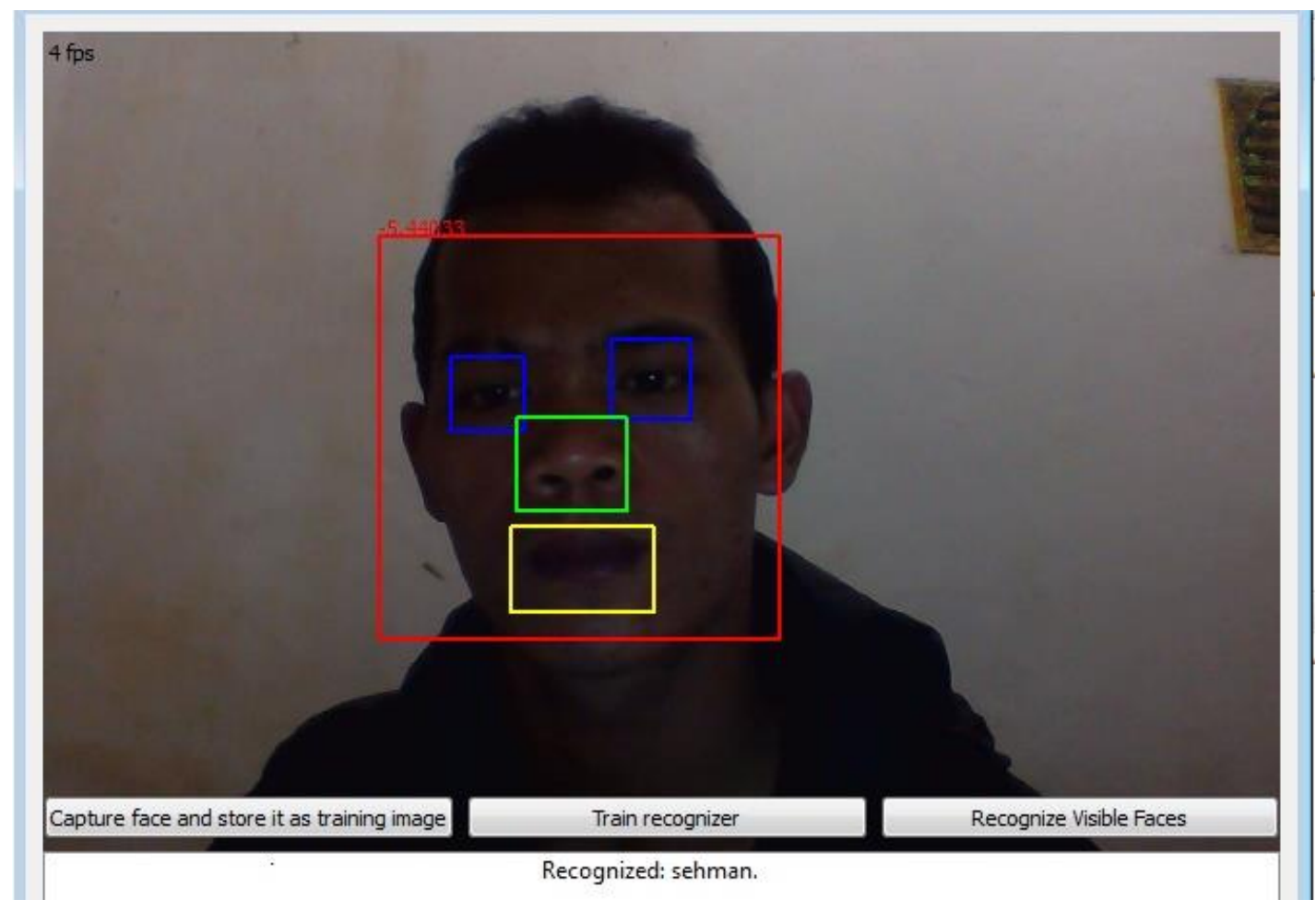

Gambar 1. Contoh Pengenalan Wajah 
Sistem pengenalan wajah ini disesuaikan pada wajah yang telah disimpan di database

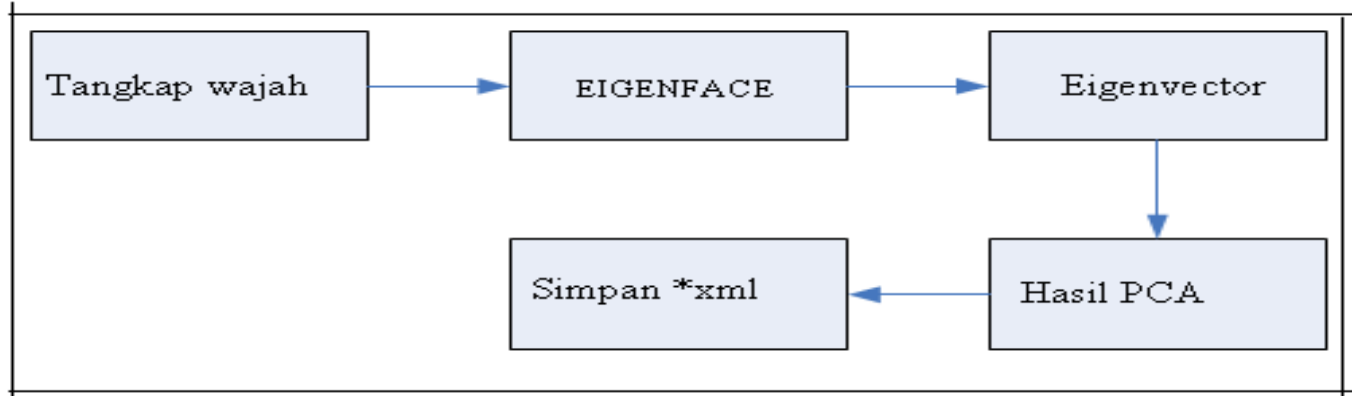

\subsection{Pengkoneksian Microcontroller}

Program ini dibuat untuk mengkoneksikan antara camera dan bunyi alarm serta kunci otomatis pada pintu mobil, tentunya dengan menjalankan intruksi dari program melalui port serial yang dimiliki oleh microcontroller Program ini dibuat dengan menggunakan CODE VISION AVR.

Microcontroller adalah sistem komputer yang dikemas dalam sebuah IC dimana IC tersebut mengandung semua komponen pembentuk komputer seperti CPU, RAM, ROM dan port IO, microcontroller dibangun untuk mengontrol sistem tertentu.
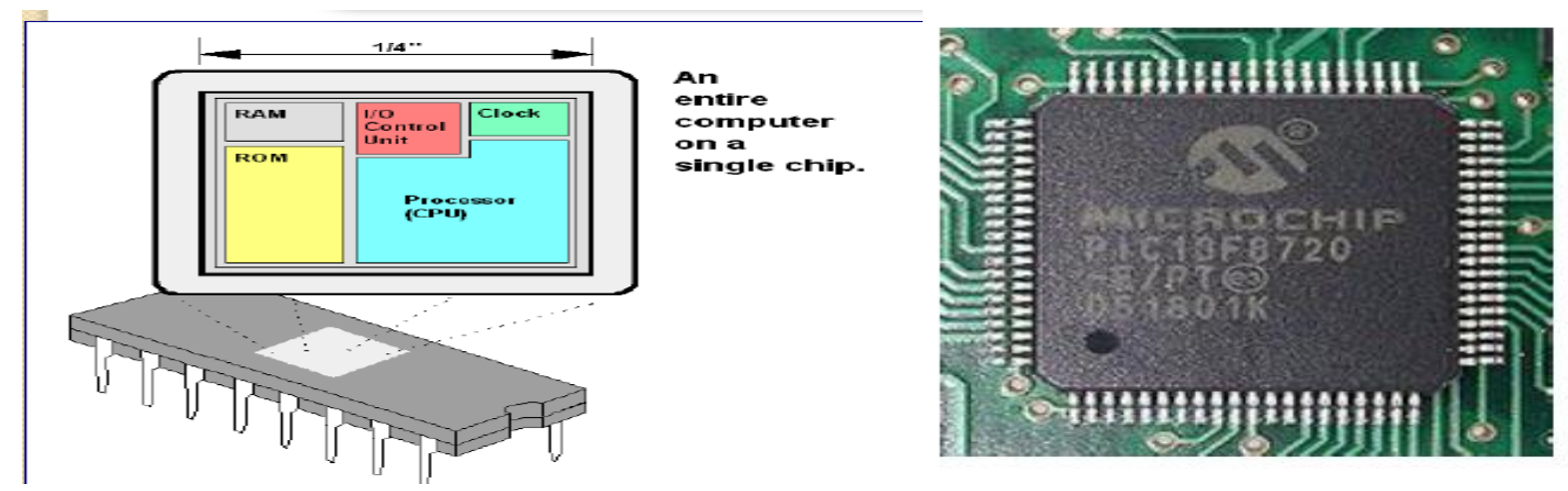

\section{Gambar 2. Microchip}

Dalam paper ini penulis mencoba untuk mensimulasikan koneksi antara kamera yang terpasang pada mobil dengan mikrontroler yang terpasang pada pintu mobil sesuai dengan gambar berikut.

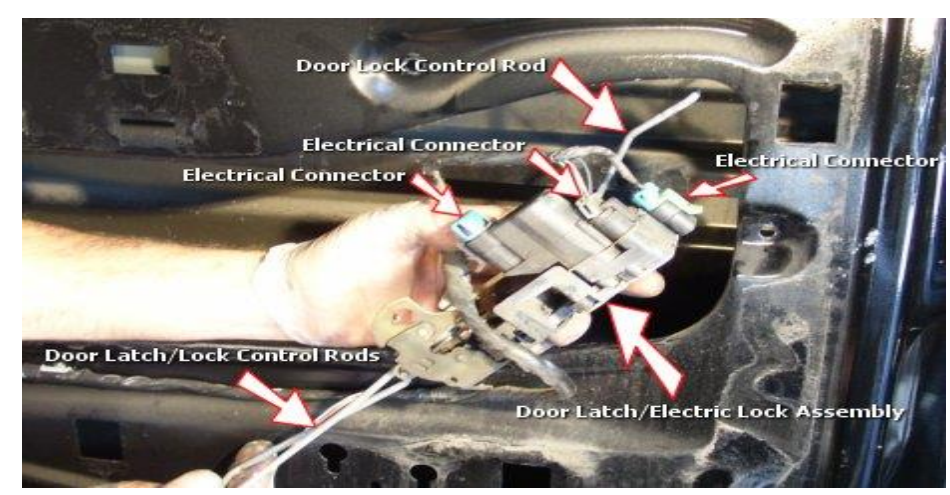

Gambar 3. Pintu Mobil 


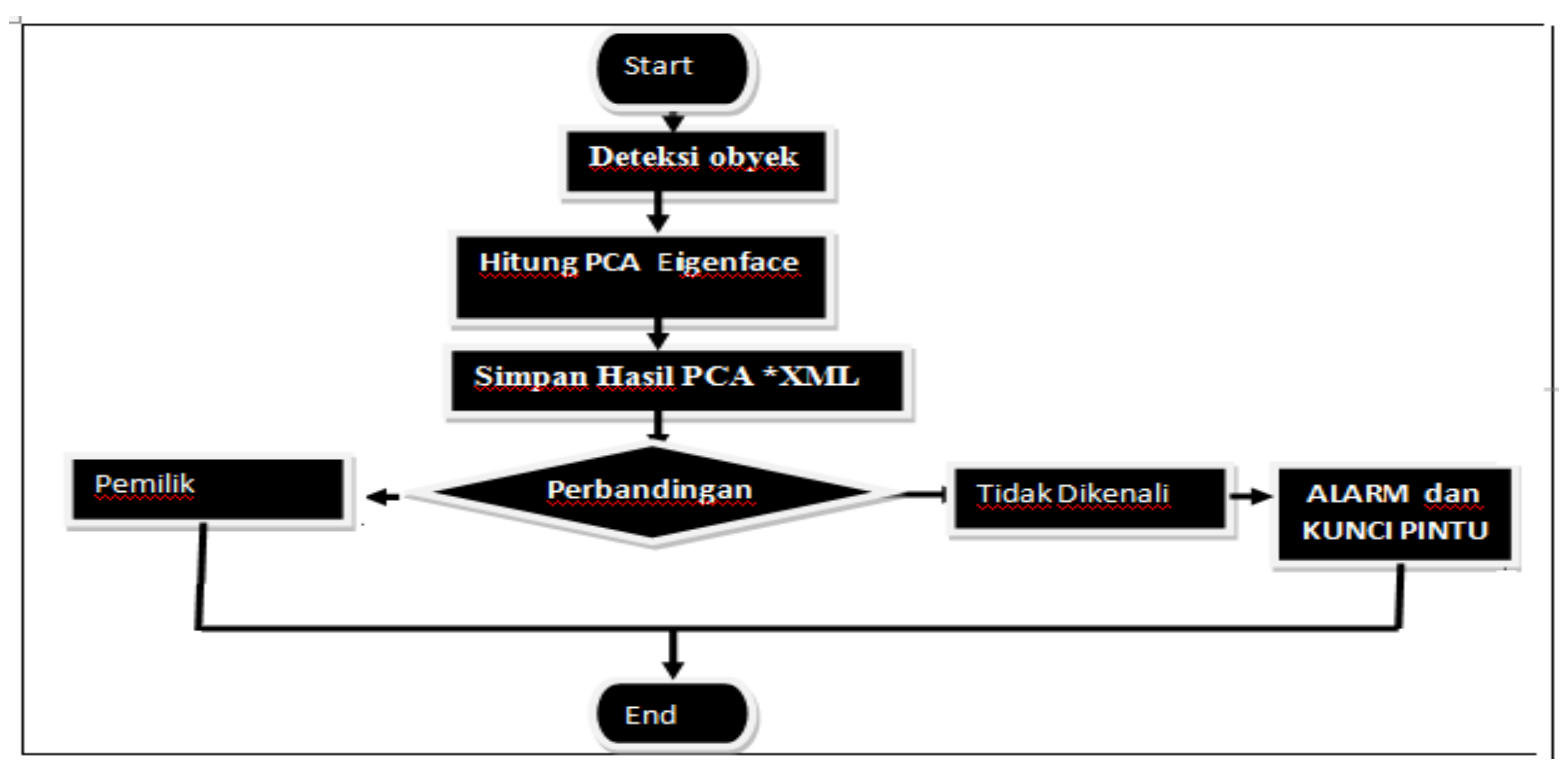

1. Kamera akan selalu aktif didalam mobil dimana pertama kamera mengenali wajah (deteksi obyek), mengirimnya ke aplikasi, kemudian menghitung nilai dan hasilnya akan berupa gambar wajah yang akan ditampilkan di LCD

2. Penghitungan nilai meliputi normalisai ukuran citra, RGB ke Grayscale, Historgram, resize atau normalisasi pencehayahaan ketika menangkap gambar sehingga hanya bagian wajah saja yang akan dihitung dan wajah akan tersimpan dengan gambar berbentuk *.Pgm.

3 Kemudian dilakukan proses PCA dengan metoda Eigenface sehingga mendapatkan Eigenvector dan eigenvalue.

4 Perbandingan wajah baru dengan wajah yang telah disimpan di database dengan menghitung antara fitur wajah, jarak yang didapat dicari nilai yang terkecil untuk perbandingan.

5 Setelah hasil perbandingan ditemukan, maka dari database system akan mengirim ke kontroler.

6 Jika nilai wajah baru lebih kecil dari nilai thershold maka wajah baru itu tidak dikenali dan system microkontroler akan otomatis mengunci pintu dan membunyikan alarm.

7 Jika nilai wajah baru lebih besar dari nilai thershold maka wajah baru itu dikenali dan system mikrokontroler akan berjalan manual sesuai kerja dari pengemudi.

\section{KESIMPULAN}

Jadi dengan adanya aplikasi yang direncanakan, penulis mengharapkan keamanan mobil lebih ditingkatkan lagi, pengujian yang dilakukan hanyalah sekedar pengenalan wajah. Dari hasil pengenalan wajah maka dapat disimpulkan bahwa:

1. Tinggi rendahnya cahaya pada obyek sangat mempengaruhi proses pendeteksian.

2. Jarak antara wajah dan camera juga mempengaruhi proses pendeteksian. 
3. Tingkat keaman pada aplikasi ini sangat sangat efektif untuk digunakan pada setiap mobil.

4. Perbandingan wajah antara pemilik mobil dan bukan pemilik mobil sangat efektif sehingga angka kemacetan jalan raya juga berkurang.

\section{DAFTAR PUSTAKA}

[1] Kouma Jean paul, "Inteligent Hom security Sysmtem", Tesis Umea University, Swedia, 2006

[2] Setya Bayu, Akhmad Hendriawan, Ronny Susetyoko, "Penerpan face Recognition dengan Metode Eigenface dalam Inteligent Security", Institut Teknologi Sepuluh Nopember(ITS) Surabaya, Kampus ITS, Sukolilo, Surabaya 60111

[3] Ahmad, Usman, "Pengolahan Citra Digital Dan Tehnik Pemograman", Yogyakarta: Graha Ilmu 2005

[4] "openCVsources", (http://sourceforge.net/projects/opencvlibrary.)

[5] Nathanael, Ryan, Yustus Eko Oktian. 2012. Face Detection dengan Adaptive Threshold dan Grayscale filter. http://uniknown.wordpress.com

[6] http://www.cognotics.com/opencv/servo_2007_series/part_4/index.html,

[7] http://www.cognotics.com/opencv/servo_2007_series/part_4/page_3.html, 